\title{
IMMEDIATE RELEASE SOLID DISPERSION TABLET OF AZILSARTAN: FORMULATION STRATEGY TO ENHANCE ORAL BIOAVAILABILITY
}

\author{
JAMEER A. TAMBOLI*, SHRINIVAS K. MOHITE
}

${ }^{*}$ Department of Pharmaceutics, Rajarambapu College of Pharmacy, Kasegaon, Tal Walwa, Dist Sangli MS India 415404

Email: jamir2u@gmail.com

Received: 31 Mar 2020, Revised and Accepted: 16 May 2020

\begin{abstract}
Objective: Objective of the present study was to develop an immediate release solid dispersion tablet to enhance oral bioavailability of Azilsartan.

Methods: Solid dispersion of azilsartan was developed using Soluplus $₫$ as a novel solubility enhancer by the solvent evaporation technique. $3^{2}$ factorial design was used in a fully randomized order to study effect of amount of azilsartan and Soluplus on solubility ( $\mu \mathrm{g} / \mathrm{ml}$ ) and \% drug dissolved in $30 \mathrm{~min}$. Prepared solid dispersion was evaluated for different micromeritic properties, saturation solubility, and wettability. Then solid dispersion of all the batches compressed into an immediate-release tablet using sodium starch glycolate as a super disintegrant. Developed tablet formulations were evaluated for various post-compression parameters and satisfactory formulation among these were further studied for Fouriertransform infrared spectroscopy (FTIR), Differential Scanning Colorimeter (DSC), X-Ray Diffraction (XRD), in vivo absorption and stability study.

Results: Results of micromeritic properties of solid dispersion showed that good flowability, compressibility, wettability, and saturation solubility. Post compression parameters of immediate-release tablets were found to be in acceptable limits. Batch ASD2 containing 40 mg Diacerein and 80 mg of Soluplus showed maximum drug release i.e. $99.82 \%$ within 30 min. Compatibility study using FTIR, DSC, and XRD showed that drug is compatible with Soluplus. In vivo absorption study showed that, 2.67 fold increase in Area Under Curve (AUC) as compared to plain Azilsartan. Relative bioavailability was found to be $267.11 \%$. Results of stability study indicate that developed formulations were stable at accelerated temperature and humidity conditions.
\end{abstract}

Conclusion: Study concluded that solid dispersion using Soluplus as a solubility enhancer is a suitable formulation strategy to enhance solubility, dissolution, and bioavailability of poorly water-soluble drug-like Azilsartan.

Keywords: Azilsartan, Soluplus, Solid dispersion, Immediate-release tablet, Bioavailability

(C) 2020 The Authors. Published by Innovare Academic Sciences Pvt Ltd. This is an open access article under the CC BY license (http://creativecommons.org/licenses/by/4.0/) DOI: http://dx.doi.org/10.22159/ijap.2020v12i4.37695. Journal homepage: https://innovareacademics.in/journals/index.php/ijap

\section{INTRODUCTION}

Solid dispersion is dispersion of one or more active ingredients in an inert carrier at solid-state prepared by fusion, solvent or solvent fusion method [1]. The solvent evaporation method is one of the most commonly used methods in the pharmaceutical industry for improving solubility of poorly water-soluble drugs [2]. This method was developed mainly for heat unstable components because drug and carrier are mixed by a solvent instead of heat as in the melting method. Therefore, this method allows use of carriers with an excessively high melting point [3]. Soluplus $\AA$ is Polyvinyl caprolactam-polyvinyl acetate-polyethylene glycol graft copolymer with amphiphilic properties, designed and developed for solid solutions. Unlike classical solubilizers, its bifunctional character can be considered as a member of the fourth generation of solid dispersions [4].

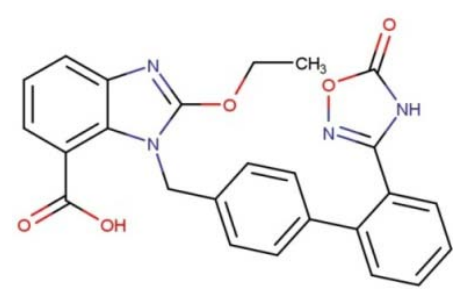

Fig. 1: Chemical structure of azilsartan $[7,8]$

Azilsartan is a selective AT1subtype angiotensin II receptor antagonist which is one of the widely used antihypertensive drug. It lowers blood pressure by blocking the action of angiotensin II at the AT1 receptor, a hormone that contracts blood vessels and reduces water excretion through the kidneys [5]. Azilsartan was discovered in 2011. But to date, it is used in form of prodrug (in salt form) azilsartan medoxomil which has been approved in both the United state and Europe. In 2012, the parent compound azilsartan was approved in Japan for the treatment of hypertension. But it has solubility problem which leads to low bioavailability, hence it is necessary to improve the solubility of Azilsartan [6-8]. Hence study was aimed to develop immediate release solid dispersion tablet of Azilsartan to enhance solubility, dissolution and hence bioavailability.

\section{MATERIALS AND METHODS}

\section{Materials}

Azilsartan was obtained from DRVL Mumbai, India as a gift sample. Soluplus ${ }^{\circledR}$ was procured from BASF Mumbai Sodium Starch Glycolate was obtained from Loba Chemie Pvt. Ltd., Mumbai. All other chemicals used were of analytical grade.

\section{Methods}

Formulation of azilsartan solid dispersion

\section{Factorial design}

To study all the possible combinations, $3^{2}$ factorial design was constructed and conducted in a fully randomized order. Solubility $(\mu \mathrm{g} / \mathrm{ml})$ and \% drug dissolved in 30 min were selected as dependent variables and studied at three different levels of the selected independent variables (factors). Details of the selected independent variables of the $3^{2}$ factorial design are shown in table 1 . Amount of Azilsartan taken in three different concentrations viz. 35, 40 and 45 mg and the amount of soluplus was taken in three different concentrations of 40,60 and $80 \mathrm{mg}$. The range of a factor was chosen to adequately measure its effect on the response variables [9].

\section{Preparation of solid dispersion}

Nine batches (ASD-1 to ASD-9) of solid dispersions of AzilsartanSoluplus were prepared by the solvent evaporation method. Briefly, 
Soluplus was dissolved in methanol under stirring and sonicated until a clear solution was obtained. Azilsartan was added with stirring for $45 \mathrm{~min}$. The solvent was evaporated at $50{ }^{\circ} \mathrm{C}$ in an oven until the complete drying of samples. The dispersions were then pulverized using a mortar and pestle, passed through 60-mesh sieve $(250 \mu \mathrm{m})$ and stored in a desiccator until use for further studies [10, 11].

\section{Evaluation of azilsartan solid dispersion}

\section{Micromeritic properties}

Micromeritic properties of solid dispersion; like angle of repose, bulk density, tapped density, Carr's index, and Hausner's ratio was studies as per standard procedures $[12,13]$.

\section{Saturation solubility}

The saturation solubility of solid dispersion batches was determined by adding an excess amount of samples to $10 \mathrm{ml}$ of water and samples were shaken on an orbital shaker (Remi Instruments Ltd. Mumbai) for $72 \mathrm{~h}$ at $37^{\circ} \mathrm{C}$. Samples were further centrifuged at 7000 rpm for $10 \mathrm{~min}$ and the supernatant was filtered through a 0.45 micron membrane filter, suitably diluted and analyzed using a UVvisible spectrophotometer at $249 \mathrm{~nm}$ [14].

\section{Wettability study}

Drug powder and solid dispersion (3g) were placed in a sintered glass funnel $(33 \mathrm{~mm}$ i.d.). The funnel was plunged into beaker containing water such that the surface of water in the beaker remains at the same level as the powder in the funnel. Methylene blue powder $(100 \mathrm{mg})$ was layered uniformly on the surface of the powder in the funnel. The time required for wetting methylene blue powder was measured [15].

\section{Formulation of azilsartan solid dispersion immediate release tablet}

Azilsartan solid dispersion powder equivalent to $40 \mathrm{mg}$ of Azilsartan was blended with $4 \%$ super disintegrant such as sodium starch glycolate for 2 min. $0.5 \%$ magnesium stearate was added as a lubricant and a powder blend of $180 \mathrm{mg}$ (including weight of lactose as a diluent) was directly compressed in to tablet using $\mathrm{KBr}$ press $[16,17]$.

Evaluation of azilsartan solid dispersion immediate release tablet

The tablets were evaluated for the following post-compression parameters [18-20].

\section{Hardness}

Five tablets were randomly selected and tested for their hardness. Tablet was placed diametrically between the holding anvil and the piston connected to the direct force reading gauge of tester (Monsanto tester). Force was applied to the anvil and the crushing strength that just causes the tablet to break was recorded.

\section{Thickness}

Thickness of tablet is important for uniformity of tablet size. Thickness was measured using Vernier Calipers (Mitutoyo Corporation India). It was determined by checking ten tablets from each formulation.

\section{Friability}

Pre-weighed tablets $(n=10)$ were placed in Roche friabilator which was then operated for 100 revolutions ( $25 \mathrm{rpm}, 4 \mathrm{~min})$. The tablets were then dusted and reweighed to check the loss in its weight. The friability (\%) was calculated using the following equation.

$$
\text { Friability }(\%)=\frac{\text { Initial weight }- \text { Final weight }}{\text { Initial weight }} \times 100
$$

\section{Weight variation}

The average weight of 20 tablets was determined by individually weighing the tablets. By comparing the individual weights to the average weight, tablet weight variation was determined.

\section{Drug content}

Ten tablets $(180 \mathrm{mg})$ were powdered in a mortar pestle and the blend equivalent to $1 \mathrm{mg}$ of Azilsartan was weighed and dissolved in the $10 \mathrm{ml}$ volumetric flask. To this sufficient quantity of methanol was added and the flask was shaken for $10 \mathrm{~min}$. Then the volume was made with methanol. This was then filtered through nylon filter paper $(0.45 \mu \mathrm{m})$, and from filtrate exactly $1 \mathrm{ml}$ was transferred to another volumetric flask of $10 \mathrm{ml}$ and volume was made with methanol. The UV absorbance of this was taken at $249 \mathrm{~nm}$ [21].

\section{Disintegration test}

One tablet is placed in each tube of disintegration test apparatus and the basket rack is poisoned in 1 liter beaker of distilled water at $37 \pm 2{ }^{\circ} \mathrm{C}$, such that the tablets remain below the surface of the liquid on their upward movement and descend not closer than $2.5 \mathrm{~cm}$ from the bottom of the beaker.

\section{In vitro dissolution study}

In vitro dissolution study was carried out in the United States Pharmacopeia (USP) Type-II dissolution test apparatus. The dissolution medium used was $900 \mathrm{ml}$ of phosphate buffer $\mathrm{pH} 7.8$ maintained at $37.5 \pm 0.5{ }^{\circ} \mathrm{C}$. The paddle speed was kept constant at $100 \mathrm{rpm}$. Samples of $5 \mathrm{ml}$ were withdrawn at specific time interval of $5 \mathrm{~min}$. The withdrawn samples were analyzed by UV spectroscopy at the wavelength maxima of 249. The same amount of fresh phosphate buffer $\mathrm{pH} 7.8$ was used to replace at each time as amount is withdrawn for respective dissolution media [22].

Selection and evaluation of satisfactory formulations for further study

Satisfactory formulation of Azilsartan solid dispersion immediaterelease tablet was selected based on the solubility of solid dispersion and \% drug dissolution after $30 \mathrm{~min}$. Selected formulations were further studied for FTIR, DSC, XRD, [23, 24] in vivo absorption and stability study.

\section{In vivo absorption studies in albino rats}

The in vivo absorption studies for pure Azilsartan and optimized formulation of ASD2 were carried out using adult albino rats (200$250 \mathrm{~g}$ ) received from animal house of Rajarambapu College of Pharmacy, Kasegaon. The study was protocol approved by the Institutional Animal Ethical Committee of Rajarambapu College of Pharmacy, Kasegaon (1290/PO/Re/S/09/CPCSEA). Rats were divided into three groups which were control, standard and test formulation groups. The animals were kept on standard supplemented diet and water for two weeks before the experiment and maintained on it thereafter. Tablets with a dose of $5 \mathrm{mg} / \mathrm{kg}$ body weight of rats were administered by dispersing in distilled water through oral feeding pipe. Blood samples were collected through the lateral tail vein of rats at 15, 30, 45, 60, 75, $90 \mathrm{~min}$ after dosing. The blood samples were centrifuged at $7000 \mathrm{rpm}$ for $10 \mathrm{~min}$ and stored2at ${ }^{\circ} \mathrm{C}$ until analysis. The plasma concentration of the drug was determined by high-performance liquid chromatography (HPLC) $[8,25]$.

\section{Accelerated stability study}

Stability study was evaluated according to the ICH guidelines (2003) on the topic of Q1A (R2): stability testing of new drug substances and products. The optimized formulation of ASD2 was packed in polyethylene laminated aluminum foils. Samples maintained in a stability chamber under intermediate conditions and evaluated under accelerated conditions $\left(45^{\circ} \mathrm{C} \pm 2{ }^{\circ} \mathrm{C}, 75 \pm 5 \% \mathrm{RH}\right)$ with humidity and temperature control, were taken at $0,1,2$ and, 3 mo for both the conditions. Drug content and \% drug released after 30 min were evaluated for the stability study.

\section{RESULTS AND DISCUSSION}

\section{Formulation of azilsartan solid dispersion}

The full mathematical equation for solubility can be given as:

$$
\mathrm{Y} 1=+87.38-0.1183 \mathrm{XA}+11.46 \mathrm{XB}
$$


Both the Azilsartan and soluplus significantly influenced the solubility. The positive coefficient of the concentration of Azilsartan and soluplus indicate that solubility increased with an increase in the concentration of Azilsartan and soluplus.

The full mathematical equation for $\%$ dissolution can be given as:

$$
\mathrm{Y} 2=87.01+1.20 \mathrm{~A}+10.23 \mathrm{~B}-0.4525 \mathrm{AB}
$$

Azilsartan and soluplus significantly influenced the percent dissolution. The negative coefficient of the concentration of Azilsartan and positive coefficient of soluplus indicate that dissolution increased with an increase in the concentration soluplus and decreased with Azilsartan concentration.

Table 1: Composition of $3^{2}$ factorial design batches and responses

\begin{tabular}{lllllll}
\hline Batch code & & & Factor 1 & Factor 2 & Response 1 \\
\cline { 2 - 6 } & Std & Run & A: Drug & B: Polymer & Solubility ( $\boldsymbol{\mu g} / \mathbf{m l})$ \\
\hline ASD-1 & 3 & 1 & 45 & 40 & 78.39 & \% Dissolution \\
ASD-2 & 8 & 2 & 40 & 80 & 87.49 & 76.48 \\
ASD-3 & 4 & 3 & 35 & 60 & 98.96 & 86.79 \\
ASD-4 & 1 & 4 & 35 & 40 & 76.41 & 78.42 \\
ASD-5 & 6 & 5 & 45 & 60 & 84.76 & 78.23 \\
ASD-6 & 9 & 6 & 45 & 80 & 102.03 \\
ASD-7 & 2 & 7 & 40 & 40 & 97.26 \\
ASD-8 & 7 & 8 & 35 & 80 & 64.72 \\
ASD-9 & 5 & 9 & 40 & 60 & 99.82 \\
\hline
\end{tabular}

The full mathematical equation for solubility can be given as:

$$
\mathrm{Y} 1=+87.38-0.1183 \mathrm{XA}+11.46 \mathrm{XB}
$$

Both the Azilsartan and soluplus significantly influenced the solubility. The positive coefficient of the concentration of Azilsartan and soluplus indicate that solubility increased with an increase in the concentration of Azilsartan and soluplus.
The full mathematical equation for $\%$ dissolution can be given as:

$$
\mathrm{Y} 2=87.01+1.20 \mathrm{~A}+10.23 \mathrm{~B}-0.4525 \mathrm{AB}
$$

Azilsartan and soluplus significantly influenced the percent dissolution. The negative coefficient of the concentration of Azilsartan and positive coefficient of soluplus indicate that dissolution increased with an increase in the concentration soluplus and decreased with Azilsartan concentration.

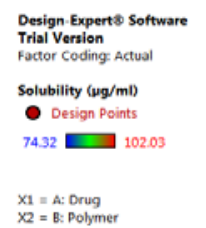

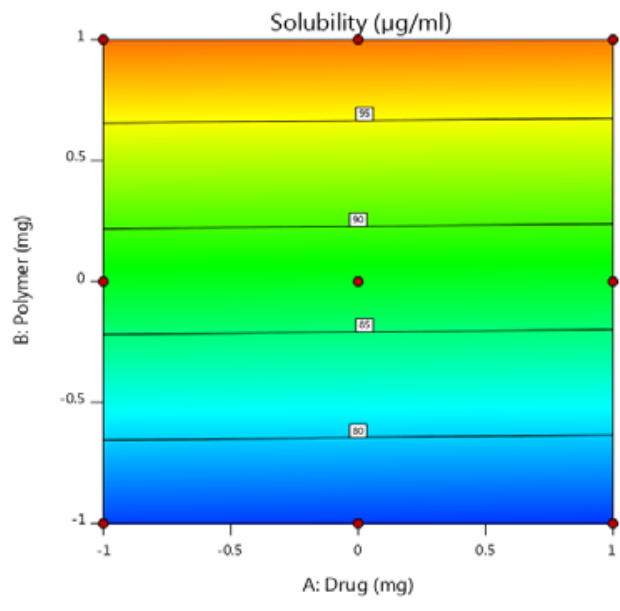

(A)

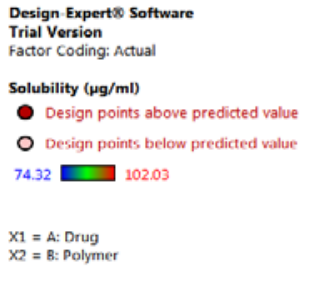

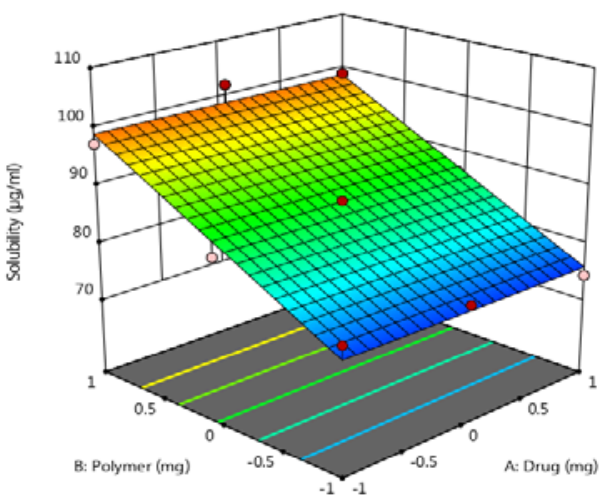

(B) 

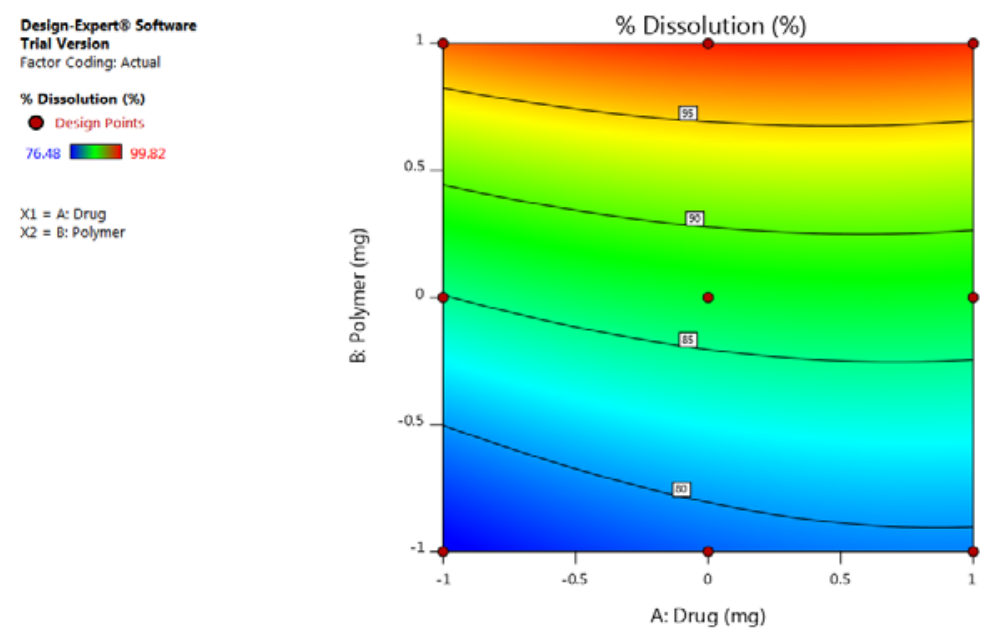

(C)
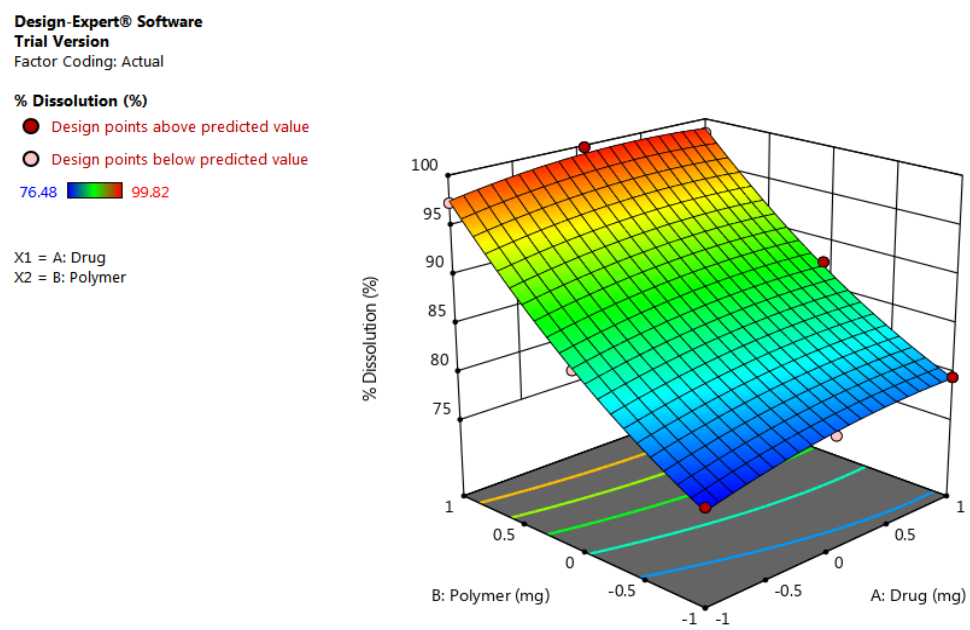

(D)

Fig. 2: (A) and (B): Counter plot and response surface plot showing the effect of variables on solubility respectively, (C) and (D): Counter plot and response surface plot showing the effect of variables on \% dissolution respectively

Table 2: Micromeritic properties and drug content of azilsartan solid dispersion

\begin{tabular}{|c|c|c|c|c|c|c|c|}
\hline Formulation & $\begin{array}{l}\text { Angle of } \\
\text { repose }\end{array}$ & $\begin{array}{l}\text { Bulk density } \\
(\mathrm{g} / \mathrm{ml})\end{array}$ & $\begin{array}{l}\text { Tapped density } \\
(\mathrm{g} / \mathrm{ml})\end{array}$ & $\begin{array}{l}\text { Compressibility } \\
\text { index }(\%)\end{array}$ & $\begin{array}{l}\text { Hausner's } \\
\text { ratio }\end{array}$ & $\begin{array}{l}\text { Wettability } \\
\text { (min) }\end{array}$ & $\begin{array}{l}\text { Solubility } \\
(\mu \mathrm{g} / \mathrm{ml})\end{array}$ \\
\hline ASD-1 & $31.6 \pm 1.32$ & $0.815 \pm 0.021$ & $0.985 \pm 0.021$ & $17.26 \pm 1.02$ & $1.21 \pm 0.05$ & $40.6 \pm 1.6$ & $74.32 \pm 2.63$ \\
\hline ASD-2 & $25.8 \pm 1.21$ & $0.731 \pm 0.032$ & $0.835 \pm 0.015$ & $12.46 \pm 1.06$ & $1.14 \pm 0.02$ & $20.2 \pm 2.2$ & $102.03 \pm 3.48$ \\
\hline ASD-3 & $29.5 \pm 2.32$ & $0.854 \pm 0.052$ & $0.987 \pm 0.066$ & $13.48 \pm 1.04$ & $1.16 \pm 0.07$ & $30.4 \pm 1.4$ & $84.76 \pm 2.66$ \\
\hline ASD-4 & $29.6 \pm 2.14$ & $0.726 \pm 0.017$ & $0.941 \pm 0.025$ & $22.85 \pm 1.05$ & $1.30 \pm 0.03$ & $32.5 \pm 2.7$ & $78.39 \pm 314$ \\
\hline ASD-5 & $28.2 \pm 1.89$ & $0.801 \pm 0.029$ & $0.984 \pm 0.048$ & $18.60 \pm 1.21$ & $1.23 \pm 0.08$ & $29.4 \pm 1.6$ & $86.42 \pm 3.69$ \\
\hline ASD-6 & $26.3 \pm 1.22$ & $0.748 \pm 0.058$ & $0.856 \pm 0.069$ & $12.62 \pm 1.07$ & $1.14 \pm 0.04$ & $22.6 \pm 1.8$ & $98.96 \pm 2.84$ \\
\hline ASD-7 & $30.1 \pm 1.54$ & $0.723 \pm 0.048$ & $0.965 \pm 0.047$ & $25.08 \pm 1.11$ & $1.33 \pm 0.06$ & $35.3 \pm 2.5$ & $76.81 \pm 2.97$ \\
\hline ASD-8 & $26.4 \pm 2.01$ & $0.763 \pm 0.034$ & $0.914 \pm 0.066$ & $16.52 \pm 1.09$ & $1.20 \pm 0.08$ & $25.4 \pm 1.4$ & $97.26 \pm 3.01$ \\
\hline ASD-9 & $27.3 \pm 1.22$ & $0.7 \pm 0.088$ & $0.89 \pm 0.052$ & $21.35 \pm 1.08$ & $1.27 \pm 0.07$ & $27.5 \pm 2.3$ & $87.49 \pm 3.88$ \\
\hline
\end{tabular}

All value represents mean $\pm \mathrm{SD}(\mathrm{n}=3)$

\section{Evaluation of azilsartan solid dispersion}

Results of micromeritic properties, saturation solubility, and wettability study are shown in table 2 . Solid dispersion batch ASD-2 containing $40 \mathrm{mg}$ of Azilsartan and $80 \mathrm{mg}$ of soluplus showed good flowability, compressibility, wettability, and solubility.

Results of saturation solubility indicate that as the concentration of soluplus increases it decrease wettability time and increase aqueous solubility [26].

\section{Formulation and evaluation of azilsartan solid dispersion tablet}

All batches of Azilsartan solid dispersion were successfully compressed in to tablet by direct compression method. The tablets were evaluated for the various post-compression parameters and results are shown in table 3 . Results showed that all post-compression parameters were found to be within acceptable limit with very good disintegration time and drug content. 
Table 3: Post compression parameters and reconstitution properties of azilsartan solid dispersion

\begin{tabular}{|c|c|c|c|c|c|c|}
\hline Formulation & $\begin{array}{l}\text { Hardness } \\
\left(\mathrm{Kg} / \mathrm{cm}^{2}\right)\end{array}$ & $\begin{array}{l}\text { Thickness } \\
\text { (mm) }\end{array}$ & Friability (\%) & $\begin{array}{l}\text { Weight } \\
\text { variation }\end{array}$ & $\begin{array}{l}\text { Disintegration time } \\
\text { (min) }\end{array}$ & Drug content (\%) \\
\hline ASD-1 & $4.2 \pm 0.32$ & $3.50 \pm 0.04$ & $0.58 \pm 0.06$ & Passes & $1.45 \pm 0.05$ & $95.48 \pm 1.06$ \\
\hline ASD-2 & $3.5 \pm 0.24$ & $3.49 \pm 0.02$ & $0.52 \pm 0.05$ & Passes & $0.78 \pm 0.02$ & $98.97 \pm 0.25$ \\
\hline ASD-3 & $4.01 \pm 0.35$ & $3.51 \pm 0.01$ & $0.52 \pm 0.06$ & Passes & $1.25 \pm 0.05$ & $97.02 \pm 1.29$ \\
\hline ASD-4 & $3.8 \pm 0.58$ & $3.53 \pm 0.02$ & $0.60 \pm 0.04$ & Passes & $1.5 \pm 0.08$ & $96.98 \pm 1.02$ \\
\hline ASD-5 & $4.2 \pm 0.22$ & $3.50 \pm 0.04$ & $0.62 \pm 0.05$ & Passes & $0.9 \pm 0.03$ & $97.21 \pm 1.8$ \\
\hline ASD-6 & $3.6 \pm 0.27$ & $3.52 \pm 0.03$ & $0.57 \pm 0.06$ & Passes & $1.27 \pm 0.08$ & $98.25 \pm 2.1$ \\
\hline ASD-7 & $3.8 \pm 0.29$ & $3.54 \pm 0.02$ & $0.62 \pm 0.08$ & Passes & $1.30 \pm 0.05$ & $96.78 \pm 1.18$ \\
\hline ASD-8 & $4.2 \pm 0.35$ & $3.51 \pm 0.05$ & $0.65 \pm 0.07$ & Passes & $0.75 \pm 0.03$ & $97.29 \pm 1.8$ \\
\hline ASD-9 & $3.8 \pm 0.33$ & $3.50 \pm 0.06$ & $0.52 \pm 0.03$ & Passes & $1.20 \pm 0.09$ & $97.36 \pm 2.8$ \\
\hline
\end{tabular}

All value represents mean \pm SD $(n=3)$

\section{In vitro dissolution study}

The results of in vitro dissolution study are shown in fig. 3. It showed that \% drug releases of all batches within $30 \mathrm{~min}$ are enhanced as compared to plain Azilsartan. Results also indicated that, as the concentration of soluplus increases, drug release also increases. Batch ASD-2 containing $40 \mathrm{mg}$ Azilsartan and $80 \mathrm{mg}$ of Soluplus showed maximum drug release i.e. $99.82 \%$ within $30 \mathrm{~min}$.

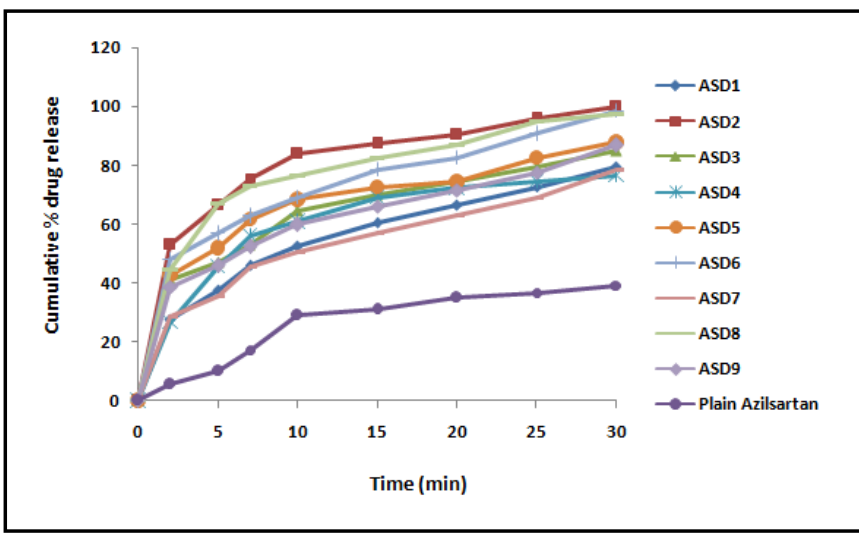

Fig. 3: Cumulative \% drug release of Azilsartan Solid Dispersion tablets compared with plain azilsartan (All value represents mean \pm SD ( $=3$ ))

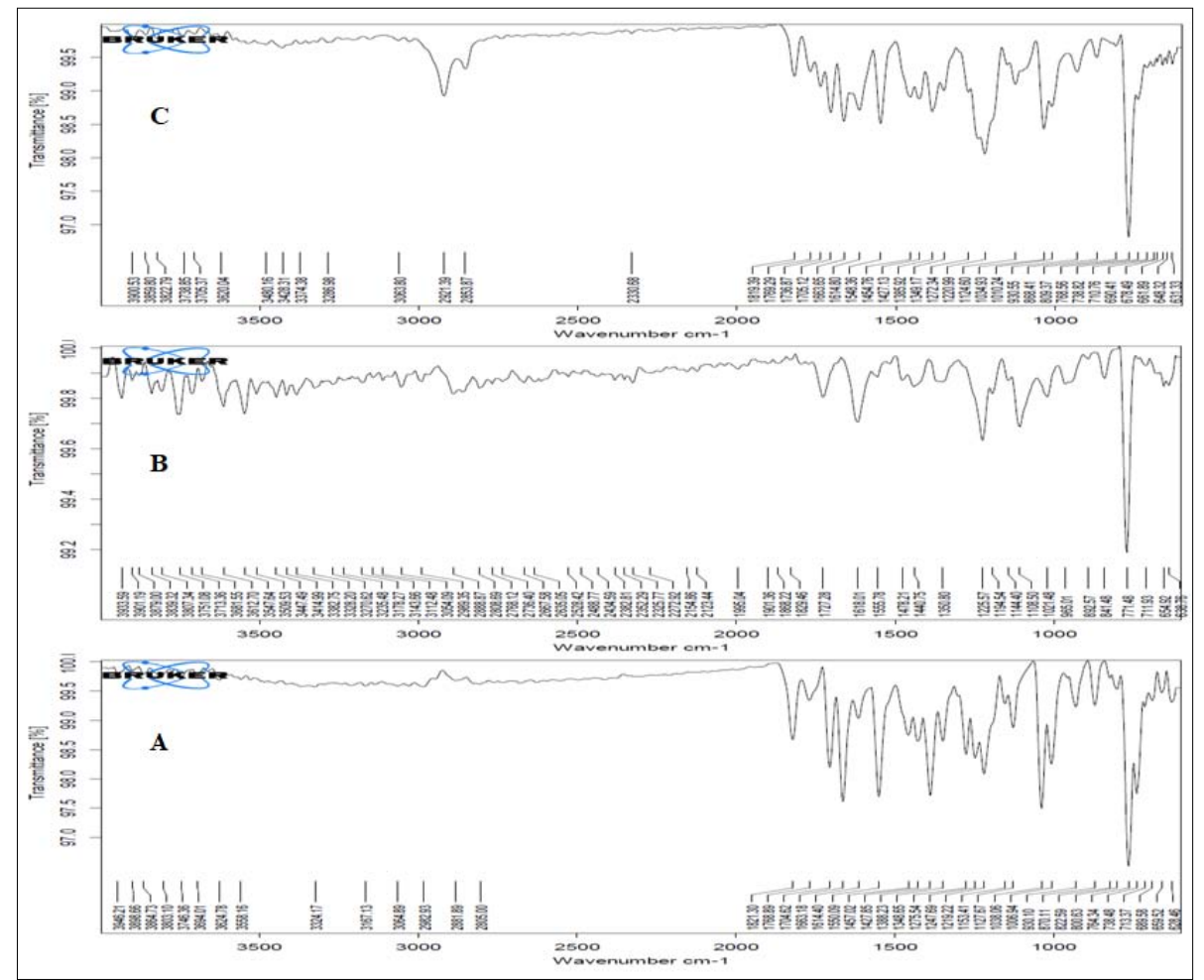

Fig. 4: FTIR spectrum of A: Azilsartan, B: Soluplus, C: Formulation ASD-2 
From the results of solubility of solid dispersion and \% drug dissolution after $30 \mathrm{~min}$ formulation of batch ASD-2 was considered as a satisfactory formulation and used for further evaluation [27].

\section{Fourier transform infrared spectroscopy (FTIR) study}

Results of the FTIR study of Azilsartan, Soluplus and formulation ASD-2 are shown in fig. 4. Results indicate that all characteristic peaks of Azilsartan have retained in the FTIR spectra of formulation ASD-2. The deformation of characteristic peaks of azilsartan in formulation may be due to the formation of the amorphous state of
Azilsartan. Hence results indicated no Imperative indication of chemical interaction between Azilsartan and Soluplus, which confirms the stability of Azilsartan in solid dispersion [28].

\section{Differential scanning calorimetry (DSC)}

Results of DSC study of Azilsartan, Soluplus and formulation ASD-2 are shown in fig. 5. It shows a sharp endothermic peak of Azilsartan at $208.52{ }^{\circ} \mathrm{C}$. The formulation ASD-2 exhibit retained small endothermic peak of azilsartan at 214.73 and it may be due to molecular dispersion of Azilsartan in Soluplus.

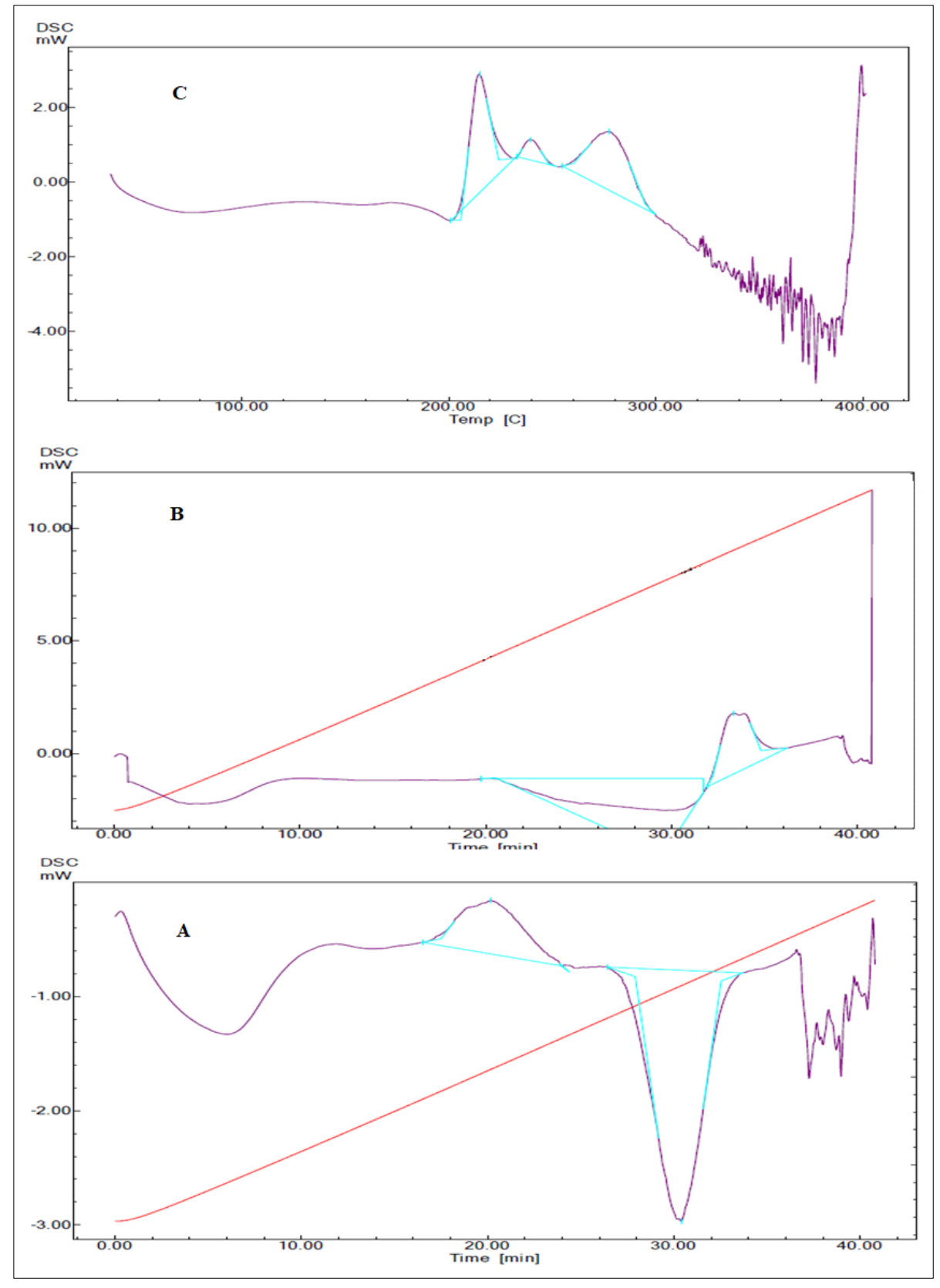

Fig. 5: DSC thermogram of A: Azilsartan, B: Soluplus, C: Formulation ASD-2

\section{X-ray diffraction studies (XRD)}

The powder X-ray diffractogram of Azilsartan, Soluplus and formulation ASD-2 are shown in fig. 6. The powder X-ray diffractogram of pure Azilsartan showed numerous distinctive peaks at that indicated a high crystallinity. The height of the characteristic peaks of azilsartan was remarkably reduced in case of diffractogram of formulation ASD-2 at low concentrations may have converted to a metastable amorphous form or may have dissolved in the matrix system [29]. 


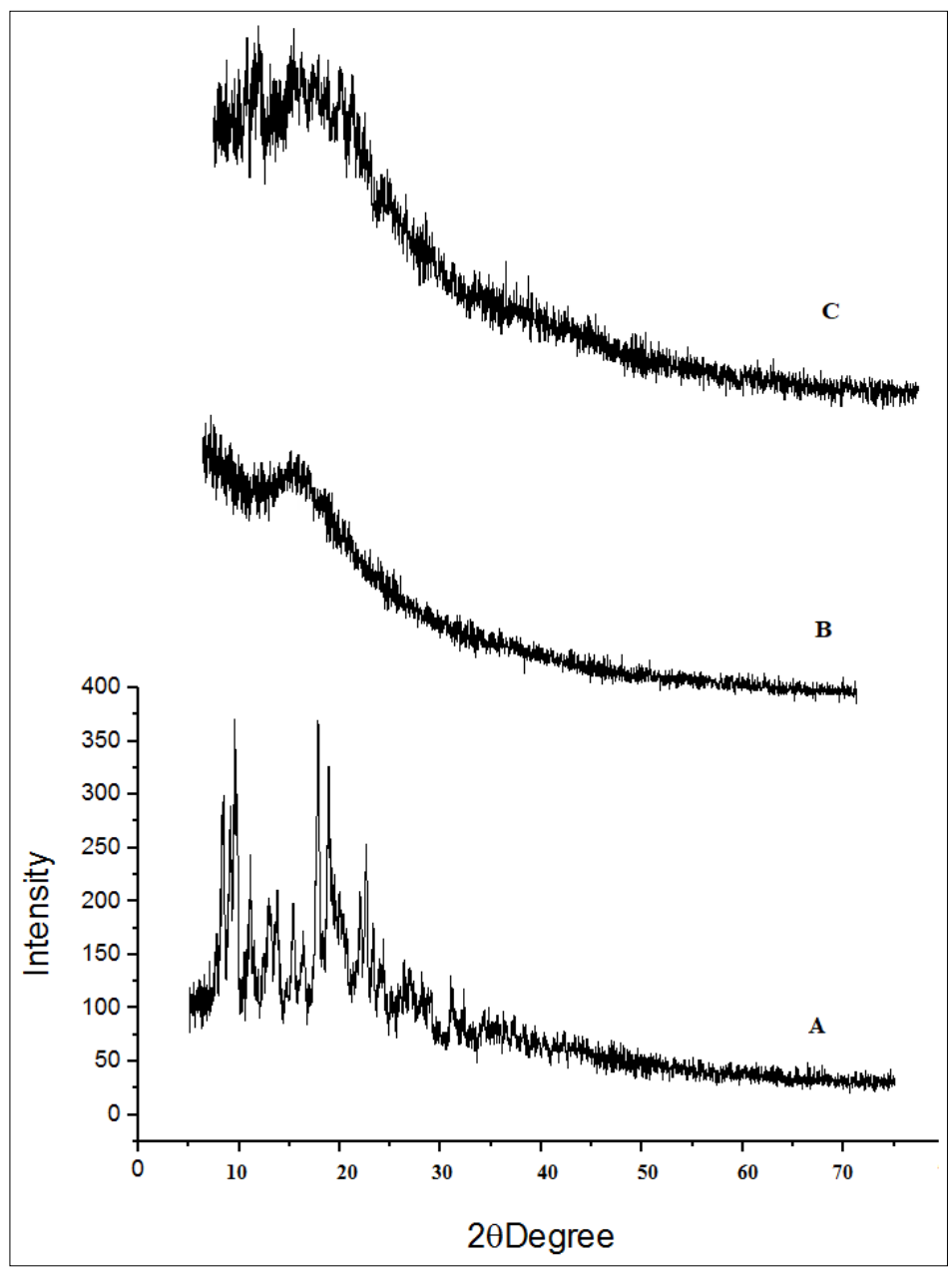

Fig. 6: XRD of A: Azilsartan, B: Soluplus, C: Formulation ASD-2

\section{In vivo absorption study of azilsartan solid dispersion tablet}

The mean plasma concentration-time curves for pure Azilsartan and Formulation ASD-2 after oral administration to albino rats are shown in fig. 7. The $\mathrm{T}_{\max }$ and $\mathrm{C}_{\max }$ were obtained directly from the curves. It was indicated that $C_{\max }$ was $31.59 \pm 3.95 \mu \mathrm{g} / \mathrm{ml}$ for pure
Azilsartan and $58.93 \pm 3.63 \mu \mathrm{g} / \mathrm{ml}$ for Formulation ASD-2 respectively, while the $\mathrm{T}_{\max }$ was 1 hour. AUC values for pure Azilsartan and Formulation ASD-2 were found 89.1 and $238.6 \mu \mathrm{g}$ $\mathrm{h} / \mathrm{ml}$ respectively. There are 2.67 fold increases in AUC. The relative bioavailability of immediate-release solid dispersion tablet compared with pure Azilsartan was 267.11\%.

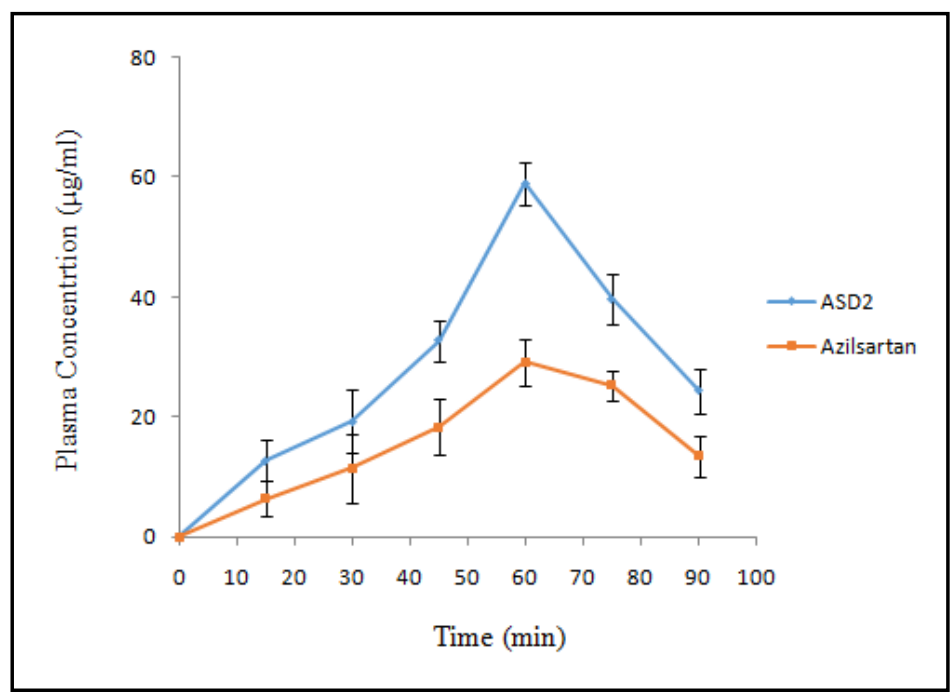

Fig. 7: Plasma concentration-time profile of ASD2 and Azilsartan (All value represents mean $\pm S D(n=3)$ ) 
Table 4: Stability study of ASD2 formulation

\begin{tabular}{llll}
\hline Formulation & Sampling time & & \\
\cline { 2 - 4 } & $\mathbf{0}$ mo & $\mathbf{1}$ mo & $\mathbf{2}$ mo \\
\hline \% Drug released after 30 min & $99.82 \pm 1.36$ & $99.56 \pm 1.78$ & $98.96 \pm 1.63$ \\
Drug content (\%) & $98.97 \pm 0.25$ & $98.85 \pm 1.02$ & $98.65 \pm 1.15$ \\
\hline
\end{tabular}

All value represents mean $\pm S D(n=3)$

\section{Accelerated stability study}

The stability data of formulation ASD2 is summarized in tables 4 . After accelerated stability study, there were no significant changes in drug content and \% Drug released after 30 min. Hence this formulation was found to be stable.

\section{CONCLUSION}

In the present study oral bioavailability of poorly water-soluble drug was enhanced using solid dispersion as a formulation strategy. The effect of different process parameters was studied using $3^{2}$ factorial design. Significant effect of independent variable i.e. concentrations of drug and soluplus on Solubility and \% dissolution was observed. The coefficient of concentration of soluplus is much more than the coefficient of concentration of a drug. This indicates that there is a very strong effect of the concentration of soluplus on solubility than the effect of conc. of a drug. Coefficient of concentration of soluplus is much more than coefficient of concentration of drug. This indicates that there is a very strong effect of concentration of soluplus on \% dissolution than the effect of conc. of drug. Developed solid dispersion immediate-release tablet showed acceptable postcompression tablet properties. From the results of the in vitro dissolution study, it can be concluded that dissolution rate was enhanced as compared to pure Azilsartan. In vivo absorption study revealed that an increase in relative bioavailability of immediaterelease Azilsartan solid dispersion tablet as compared to pure Azilsartan. Hence study concluded that the immediate-release tablet of solid dispersion is a very good formulation strategy to enhance solubility, dissolution and oral bioavailability of poorly watersoluble drug such as Azilsartan.

\section{ACKNOWLEDGMENT}

Authors are thankful to DRVL Mumbai, India, and BASF Mumbai, for providing gift sample of Azilsartan and Solubplus ${ }^{\circledR}$ respectively. Authors are also thankful to Principal Rajarambapu College of Pharmacy, Kasegaon for providing the necessary facility to perform the work.

\section{FUNDING}

Nil

\section{AUTHORS CONTRIBUTIONS}

Both the authors contributed equally to performing this study and for writing the manuscript.

\section{CONFLICT OF INTERESTS}

The authors declare that no conflict of interest.

\section{REFERENCES}

1. Deshmukh DB, Gaikwad PD, Bankar VH, Pawar SP. Dissolution enhancement of poorly water soluble diacerein by solid dispersion technique. J Pharm Sci Res 2010;2:734-39.

2. Patil AN, Shinkar DM, Saudagar RB. Solubility enhancement by solid dispersion. Int J Curr Pharm Res 2017;9:15-8.

3. Tachibana T, Nakamura A. A method for preparing an aqueous colloidal dispersion of organic materials by using water-soluble polymers: dispersion of B-carotene by polyvinylpyrrolidone. Kolloid-Zeitschrift Zeitschrift Polym 1965;203:130-3.

4. Shamma RN, Basha M. Soluplus®: a novel polymeric solubilizer for optimization of carvedilol solid dispersions: formulation design and effect of method of preparation. Powder Tech 2013;237:406-14.

5. Sum L. Azilsartan a newly approved angiotensin ii receptor blocker. Cardiol Rev 2011;19:300-4.
6. Fernanda SL, Lavinia SF, Corinna WS. Heart and blood medications. In: Christof S, Paul P, Richard KM. Drugs during pregnancy and lactation treatment options and risk assessment. $3^{\text {rd }}$ ed. Academic Press: United States; 2015. p. 193-223.

7. Tamboli JA, Mohite SK. Self microemulsifying immediate release tablet of azilsartan for enhanced dissolution. Res J Pharm Tech 2020;13:197-202.

8. Naykode MD, Bhagwat DA, Jadhav SD, More HN. Analytical and bioanalytical method for quantification of pure azilsartan, not its salts by RP-HPLC. Res J Pharm Tech 2017;10:708-14.

9. Yan Xie, Guowen Li, Xiurong Yuan, Zhenzhen Cai, Rong Rong. Preparation and in vitro evaluation of solid dispersions of total flavones of hippophae rhamnoides L. AAPS PharmSciTech 2009;10:631-40.

10. Alireza Homayouni, Fatemeh Sadeghi, Ali Nokhodchi, Jaleh Varshosaz, Hadi Afrasiabi Garekanif. Preparation and characterization of celecoxib dispersions in soluplus $\AA$ : comparison of spray drying and conventional methods. Iran J Pharm Sci 2015;14:35-50.

11. Rao MRP, Chandanshive PA. Preparation and characterization of solid dispersions for solubility enhancement of BCS class II drug. WJPPS 2017;6:1852-69.

12. Aulton ME. Pharmaceutics: the science of dosage form design. Second Edn. Livingstone C. Elsevier Science Ltd; 2002. p. 315-20.

13. More HN, Hajare AA. Practical physical pharmacy. Career Prakashan, Nashik. 2nd; 2010. p. 29-131.

14. Chaulang G, Patil K, Ghodke D, Khan S, Yeole P. Preparation and characterization of solid dispersion tablet of furosemide with crospovidone. Res J Pharm Tech 2008;1:20-7.

15. Lefebvre C, Barthelemy AM, Hermann G. An attempt at bringing to light a "phase inversion" in a binary mixture of two-dimensional rounded particles. Drug Dev Ind Pharm 1988;14:2443-65.

16. Kang MJ. Immediate release of ibuprofen from fujicalin ${ }^{\circledR}$-based fast dissolving self-emulsifying tablets. Drug Dev Ind Pharm 2011;37:1298-305.

17. Panigrahi R, Chowdary KA, Mishra G, Bhowmik M, Behera S. Formulation of fast dissolving tablets of Lisinopril using combination of synthetic superdisintegrants. Asian J Pharm Tech 2012;2:94-8.

18. Lachman L, Liberman HA. Theory and practice of industrial pharmacy. $3^{\text {rd }}$. Varghese publishing house, Mumbai; 1990. p. 171-94.

19. Banker GS, Anderson NR. Tablet. In: Leon Lachman, HA Lieberman, JL Kanig. $3^{\text {rd }}$ ed. The theory and practice of industrial pharmacy. Varghese publishing house, Mumbai; 1990. p. 296-302.

20. Indian Pharmacopoeia Government of India, Ministry of Health and Family Welfare. Vol. II. The controller of publications. New Delhi; 1996. p. 734-6.

21. Budiman A, Sopyan I, Riyandi DS. Enhancement of glibenclamide dissolution rate by solid dispersion method using HPMC and PVP. Int J Appl Pharm 2019;11:19-24.

22. Tianshu L, Yinghua S, Dawei D, Qi Z, Rui F, Zhonggui H, et al. Study on enhanced dissolution of azilsartan-loaded solid dispersion, prepared by combining wet milling and spraydrying technologies. AAPS PharmSciTech 2017;18:473-80.

23. Lesinski L, Duschmale UJ. Differential scanning calorimetry, physical chemistry. Wintersemester 2006;7:1-8.

24. Aggarwal AK, Singh S. Physicochemical characterization and dissolution study of solid dispersions of diacerein with polyethylene glycol 6000. Drug Dev Ind Pharm 2011;37:1181-91.

25. Chopra DK, Kar DM, Sahu PK. Improvement of oral bioavailability of azilsartan medoxomil by lipid based liquisolid 
compacts: in vitro and in vivo evaluation. Int Res J Pharm 2018;9:134-9.

26. Linn M, Collnot EM, Djuric D, Hempel K, Fabian E, Kolter K, et al Soluplus $\AA$ as an effective absorption enhancer of poorly soluble drugs in vitro and in vivo. Eur J Pharm Sci 2012;45:336-43.

27. Shah I, Bhatt S, Yadav A. Enhancement of solubility and dissolution of nebivolol by solid dispersion technique. Int J Pharm Pharm Sci 2014;6:566-71.
28. Najmuddin $\mathrm{M}$, Khan $\mathrm{T}$, Mohsin AA, Shelar $\mathrm{S}$, Patel V. Enhancement of dissolution rate of ketoconazole by solid dispersion technique. Int J Pharm Pharm Sci 2010;2:132-6.

29. Guntaka Pr, Lankalapalli S. Solubility and dissolution enhancement of ivacaftor table ts by using solid dispersion technique of hot-melt extrusion-a design of experimental approach. Asian J Pharm Clin Res 2019;12:356-63. 